\title{
Stings from Euscorpius flavicaudis (De Geer, 1778) (Scorpiones, Euscorpiidae) during pregnancy: a clinical case report
}

\author{
Dutto M (1), Dutto L (2), Bertero M (3), Goyffon M (4)
}

(1) Medical-Entomology Consultant, Santa Croce e Carle Hospital, Cuneo, Italy; (2) Department of Emergency Medicine, Santa Croce e Carle Hospital, Cuneo, Italy; (3) Department of Dermatology, Santa Croce e Carle Hospital, Cuneo, Italy; (4) Natural History Museum, Paris, France.

\begin{abstract}
We report a case in which a 21-week pregnant woman was stung by a Euscorpius flavicaudis (De Geer, 1778) scorpion. Symptoms and signs experienced by the patient were the same as those documented in the literature and with no ill-effects for the pregnancy. Envenoming was local and of low degree of intensity. It is important to emphasize that the patient was stung in her home, which differs from stings in most other parts of the world, in which scorpionism is mostly a risk in outdoor areas.
\end{abstract}

Key words: Euscorpius flavicaudis, sting, scorpionism, pregnant woman, clinical, symptoms.

\section{INTRODUCTION}

Scorpionism, the term for local and systemic toxicological reactions to scorpion stings, comprises to humans an accidental event involving involuntary contact with a scorpion during routine activity at work or home, or in outdoor areas (1). Scorpion stings occur more frequently in developing countries and are usually rare in Europe.

As to the danger posed to humans by scorpions, it is important to remember that all scorpion species are endowed with toxic secretions that lead to post-sting reactions (scorpionism), but only a few species worldwide (approximately 30) have toxins capable of causing serious systemic reactions in humans $(1,2)$.

There are many cases reported in the literature that refer to scorpionism caused by highly toxic species. Yet, little has been reported about the pathological reactions to species that are mildly toxic to humans, despite the fact that they still pose medical concern (3).

Scorpions of the genus Euscorpius, as indicated by the literature, secrete toxins that provoke local and short term (30-90 minutes) reactions in humans (4-6). Data are scarce with regard to scorpion stings in pregnant women. It is known that animal venoms can be particularly dangerous to both mother and fetus, even if only due to the painful symptoms and agitation that may provoke uterine contractions (7).

Most of previously reported cases of scorpionism in the literature are related to notoriously venomous species found throughout the Mediterranean (North Africa), tropical and subtropical areas (8), whereas there are no studies or references to cases concerning species native to Italy, about whose toxic secretions not much is known.

In terms of scorpion distribution, Italy is a unique case. Several types of scorpions make 
their home virtually everywhere in the world; being a few species of the family Buthidae and one or more species of other non-Buthidae families, formerly known as chactoid scorpions, dominant. The only autochthonous scorpions in Italy are from the family Euscorpiidae, especially large-sized species, such as Euscorpius italicus (Herbst, 1800) that can reach $5 \mathrm{~cm}$ in length or more. Buthidae scorpions are not found in Italian territory. In Europe, there is a gap in species distribution: in the west of Italy (France and Spain), the genus Buthus sp. of family Buthidae is found; while in the eastern portion (the Balkans), the genus Mesobuthus sp. is found in place of Buthus. Scorpions that are medically important, i.e. dangerous to humans, generally belong to the family Buthidae, with rare exceptions.

\section{CASE REPORT}

A 37-year-old pregnant woman who was 21 weeks pregnant presented at the emergency department (ED) of the Santa Croce e Carle hospital in Cuneo, in northwestern Italy, after having been stung by a scorpion in her home during routine housecleaning activities. The scorpion had been caught and was brought in for identification by the hospital entomological consultant who identified it as Euscorpius flavicaudis (De Geer, 1778) (Figure 1).

The patient was stung on the palm of the left hand and complained of intense burning pain at the sting site where the aculeus had penetrated the skin, resulting in a $3-4 \mathrm{~mm}$ red area. The subject had no other systemic symptoms. A full blood count, liver function and coagulation tests, electrolyte blood levels and other routine laboratory tests were all normal, as were the results of urinalysis. An electrocardiogram recorded an hour after the sting revealed nothing unusual. In the meantime pain and inflammation diminished. A gynecological exam showed normal abdominal findings and no uterine contractions. Given the low toxicity of the species involved, the woman was discharged an hour and a half after the sting and advised to seek her family physician in the event of any new symptoms associated with the sting.

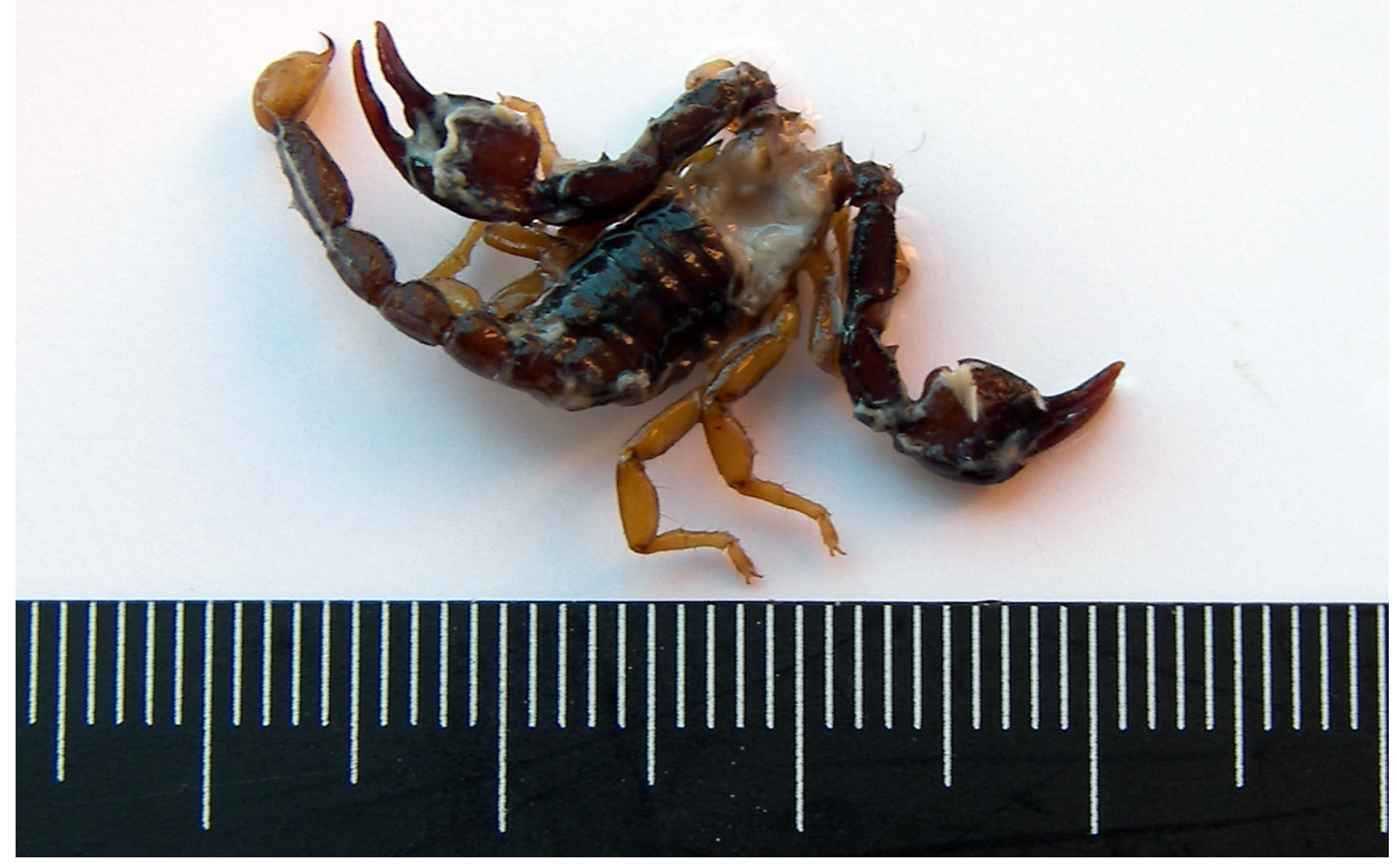

Figure 1. Euscorpius flavicaudis that stung the subject of the present report (photo by M. Dutto). 


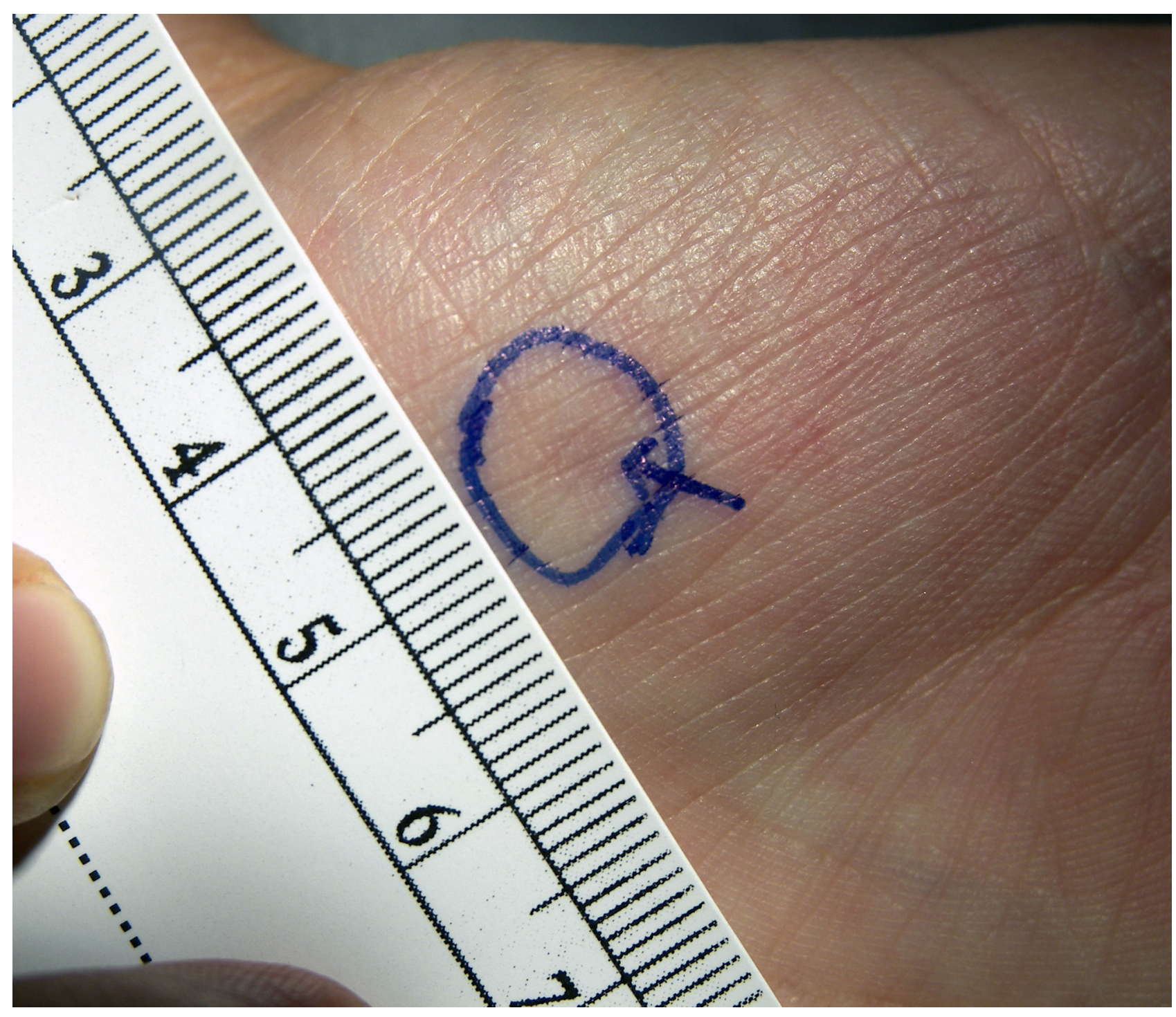

Figure 2. Sting site at the time the patient was discharged from hospital. The circle indicates the maximum area of the redness while the arrow shows the point at which the aculeus penetrated the skin (photo by M. Dutto).

At the time she was discharged the redness had significantly diminished (Figure 2) and the subject reported a light burning sensation although the sting site was no longer noticeable.

Fifteen days after the sting no gynecological problems emerged and the pregnancy proceeded normally to term.

\section{DISCUSSION}

Scorpionism in pregnancy may represent an important medical emergency, especially in cases which the involved species secretes toxins that have systemic activity.

Experimental observations have shown that stings of some buthid scorpions may provoke abnormal uterine contractions in pregnant victims or even placental abruption, which results in dystocia (9). Such reactions are caused by scorpions of the family Buthidae, whose venom contains toxins which bind to sodium channels. Non-Buthidae species have not been included in these descriptions. The present observations confirm the usually benign outcomes of Euscorpiid stings, regardless of their size, even in pregnant women. In Italy, only scorpion stings of exotic Buthidae species would be harmful. Such animals are found in Italy only as a result of illegal or accidental importation.

Envenoming during pregnancy from highly poisonous scorpions (species found in North Africa, the Southern United States, Mexico 
and Central America) may provoke severe consequences and even long-lasting symptoms (rare), when compared to normal subjects in whom the venom-related symptoms are rather rapid and dissipate within the first 24 hours $(2,8)$. The major risks of scorpionism in pregnancy (fetal death, abnormal development, placental abruption) occur in the second and third trimesters and are due to biological interferences caused by the venom which often lead to an increase in glucose levels, increase of blood polymorphonucleated (PMN) leukocytes, alteration of the lipid metabolism and electrolyte balance (10-13). Furthermore, an increase in PMN leukocytes may, in turn, increase serum levels of inflammatory kinins and interleukins which then interfere at the site of the placental barrier.

The complex interactions between venom and a pregnant woman's metabolism may cause severe problems for the fetus, even several weeks after the original envenoming, when venom acute effects have worn off $(8,14)$.

In the present report, the absence of systemic toxicity caused by Euscorpius was confirmed. The case of a pregnant woman stung by a scorpion demanded special attention, particularly prompt identification of the scorpion species involved.

In the case of stings from Euscorpius, management of envenoming of pregnant women does not differ from that of other victims, as indicated in the literature (4). However, it is always wise to carry out basic blood tests and to observe the patient for at least 2 to 4 hours after the event, particularly if the person experiences intense pain. The observation must be increased in cases of uterine contractions or changes in fetal movements. In addition, it is advisable to communicate the event to the family physician for a follow-up.

In any case in which the scorpion has not been identified, it is recommended to keep the victim under observation for a minimum of 24 hours, principally in situations of intense pain, considering that the species that secrete the most toxic venom are found in Italy as a result of illegal or accidental importation (15).

Patients who have been stung by an unidentified species must be carefully observed, especially when they experience lasting pain that worsens or recurs (particularly within the first two hours after the sting). Pain is always a good way to measure the amount of injected venom, since all scorpions may also not inject their venom at the moment of stinging. It may also indicate envenoming even before the appearance of systemic symptoms (2). Biochemical alterations that suggest the onset of systemic envenoming are leukocytosis (20-40 x $10^{3} / \mathrm{mm}^{3}$ ), hyperglycemia and enzyme markers for cardiac or pancreatic necrosis $(2,16)$.

In conclusion, we state that the clinical course of envenoming from Euscorpius is the same in pregnant victims and others. Our findings also corroborate previously reported cases in the literature regarding envenoming characteristics such as locoregional pain that disappears within an hour after the sting $(4,5)$.

\section{COPYRIGHT}

(C) CEVAP 2012

\section{SUBMISSION STATUS}

Received: June 14, 2012.

Accepted: August 16, 2012.

Abstract published online: September 3, 2012.

Full paper published online: November 30, 2012.

\section{CONFLICTS OF INTEREST}

The authors declare no conflicts of interest.

\section{CORRESPONDENCE TO}

Moreno Dutto, Servizio Igiene e Sanità Pubblica ASL CN1, Via del Follone, 7- 12037 Saluzzo (CN), Italy. Phone: +39 0175 215613. Email: moreno. dutto@gmail.com.

\section{REFERENCES}

1. Goyffon M, Billiald P. Envenimations VI. Le scorpionisme en Afrique. Med Trop. 2007;67(5):43946.

2. Goyffon M, Chippaux JP. Animaux venimeux. Encyclopédie Médico-Chirurgicale, Intoxication, Pathologie du travail. Paris: Editions Techniques; 1990. p. 1-14.

3. Bawaskar HS, Bawaskar PH. Scorpion sting: update. J Assoc Physicians India. 2012;60:46-55.

4. Dutto M, Dutto L, Scaglione N, Bertero M. Euscorpius (Scorpiones, Euscorpiidae): three cases of sting in northwestern Italy. J Venom Anim Toxins incl Trop Dis. 2010;16(4):659-63.

5. Torregiani F, La Cavera C. Punture di scorpione (Euscorpius sp.) in Italia e rassegna dello scorpionismo. Minerva Med. 1990;81( Suppl 2):137-45.

6. Pastrana J, Blasco R, Erce R, Pinillos MA. Picadures y mordeduras de animales. Anales Sis San Navarra. 2003;26(1):225-41. 
7. Langley RL. A review of venomous animal bites and sting in pregnant patients. Wilderness Environ Med. 2004;15(3):207-15.

8. Ben Nasr H, Hammami TS, Sahnoun Z, Rebai T, Bouaziz M, Kassis M, et al. Scorpion envenomation symptoms in pregnant women. J Venom Anim Toxins incl Trop Dis. 2007;13(1):94-102.

9. Ben Nasr H, Hammani S, Mion G, Sahnoun Z, Chouiaekh F, Rebai T, et al. Effects of Buthus occitanus tunetanus venom on an experimental murine model of gestation. C R Biol. 2007;330(12):890-6.

10. D’Suze G, Moncada S, González C, Sevcik C, Aguilar $\mathrm{V}$, Alágon A. Relationship between plasmatic levels of various cytokines, tumor necrosis factor, enzymes, glucose and venom concentration following Tityus serrulatus scorpion sting. Toxicon. 2003;41(3):367-75.

11. Goyffon M, Vachon M, Broglio N. Epidemiological and clinical characteristics of the scorpion envenomation in Tunisia. Toxicon. 1982;20(1):337-44.

12. Soudani N, Gharbi-Chihi J, Srairi-Abid N, Yazidi CM, Planells R, Margotat A, et al. Isolation and molecular characterization of LVP1 lipolysis activating peptide from scorpion Buthus occitanus tunetanus. Biochim Biophys Acta. 2005;1747(1):47-56.
13. Andrade MV, Caramez MP, Abreu EM, Dolnikoff M, Omar ED, Velasco IT, et al. Lung compliance, plasma electrolyte levels and acid-base balance are affected by scorpion envenomation in anesthetized rats under mechanical ventilation. Comp Physiol C Toxicol Pharmacol. 2004;138(1):97-104.

14. Leibenson L, Leibenson M, Silberstein T. Antepartum fetal death following a yellow scorpion sting. Arch Gynecol Obstet. 2010;281(2):247-9.

15. Schaper A, Desel H, Ebbecke M, De Haro L, Deters $\mathrm{M}$, et al. Bites and sting by exotic pets in Europe: an 11 year analysis of 404 cases from Northeastern Germany and Southeastern France. Clin Toxicol (Phila). 2009;47(1):39-43.

16. Amitai Y. Clinical manifestations and management of scorpion envenomation. Public Health Rev. 1998;26(3):257-63. 